\title{
Statistical relationships between the North Atlantic Oscillation and international tourism demand in the Balearic Islands, Spain
}

\author{
Marcos Álvarez-Díaz ${ }^{1, *}, M^{a}$ Soledad Otero Giráldez ${ }^{2}$, Manuel González-Gómez ${ }^{2}$ \\ ${ }^{1}$ Department of Economics, and ${ }^{2}$ Department of Applied Economics, University of Vigo, Lagoas-Marcosende s/n, 36310 Vigo, Spain
}

\begin{abstract}
A large number of studies have been devoted to analyzing international tourism demand; however, even today, the impact of climate and weather on tourism receives only limited attention. We studied the empirical influence of the North Atlantic Oscillation (NAO), the most important mode of variability in northern atmospheric circulation, on international tourism demand - specifically, tourist arrivals from the UK and Germany to the Balearic archipelago (Spain). We used 2 traditional techniques usually applied in natural sciences, cross-correlation functions and the Granger causality test, as well as a novel and flexible methodology called the autoregressive distributed lag (ARDL) boundstesting approach. ARDL modeling can be a useful tool in illuminating relationships between variables. Our empirical evidence demonstrates the existence of a statistical relationship between the NAO and tourist arrivals from the UK and Germany to the Balearic Islands. The finding of a statistical relationship between the NAO and tourism suggests that this atmospheric phenomenon can be of great interest to social researchers who study international tourism flows. The NAO index can be used as an explanatory variable in tourism demand models, allowing researchers to develop parsimonious models, as well as to avoid certain economic problems (e.g. multicolinearity).
\end{abstract}

KEY WORDS: North Atlantic Oscillation - International tourism demand · Granger causality test · Cross-correlation analysis $\cdot$ Autoregressive distributed lag $\cdot$ ARDL $\cdot$ Balearic Islands

\section{INTRODUCTION}

Tourism has become one of the largest and fastestgrowing economic sectors in the world. According to the World Tourism Organization (UNWTO 2009), international tourism generated US $\$ 944$ billion in 2008, and the worldwide contribution of this sector to gross domestic product (GDP) is calculated to be $\sim 5 \%$. In spite of the importance of tourism, there is a shortage of in-depth studies on the mechanisms that drive international tourism demand. The great majority of the studies on this topic focus on a series of psychological and, above all, socio-economic factors, such as population, income level, relative prices, foreign exchange rates, and marketing expenditures on promotional activities (Law \& Au 1999, Lim 1999). Although socioeconomic factors are unquestionably relevant in explaining tourism flows, other factors could be also important, e.g. climate and weather. 1
Tourism depends on climate and weather, as many tourist activities rely heavily on specific meteorological conditions (e.g. skiing activities, seaside tourism). Therefore, it is reasonable to consider climate and weather conditions as significant determinants of international tourism demand. However, relatively little systematic research has been carried out on this topic because climate and weather are usually seen to be constant or as random factors out of the control of researchers and managers (Berrittella et al. 2006). Relatively recently, a number of studies have analyzed the impact of climate and weather variables on tourism (Agnew \& Viner 2001, Maddison 2001, Agnew \& Palutikof 2006, Parrilla et al.

\footnotetext{
${ }^{1}$ Climate and weather are meteorologically similar phenomena manifested and studied at different scales. De Freitas (2003) defines climate as the accumulation of daily and seasonal weather events over a long time period. On the other hand, weather is the condition of the atmosphere at a specific place and at a specific time
} 
2007, Scott et al. 2008). The most widely used variables were temperature, rainfall, wet days, cloud cover, humidity, sunshine, and wind speed. However, the inclusion of these variables in a tourism-demand model could lead to some econometric problems since they are highly correlated to each other (multicollinearity problems). Other researchers have constructed indices that allow summarizing the significance of climate for tourism, but they were only used to evaluate and rate recreational climates in terms of user sensitivity and satisfaction (de Freitas 2003, de Freitas et al. 2008).

One key variable that might be useful to summarize meteorological information and potentially useful to explain tourism is the recurrent pattern of atmospheric variability observed over the North Atlantic Ocean, known as the North Atlantic Oscillation (NAO). The phenomenon is formally defined as an anomalous difference in atmospheric pressure between a subtropical high-pressure belt (around the latitudes of 35 to $40^{\circ}$ in the Northern Hemisphere and centered near the Azores) and a subpolar low-pressure belt (centered over Iceland) (Hurrell et al. 2003). The NAO has an important impact on the climate variability of the Northern Hemisphere, and it has a significant influence on the temperatures, storms, precipitation, and wind speed observed predominantly in the Atlantic zone and in the Mediterranean region (Greatbatch 2000). For this reason, analysis of the NAO can be of great interest for tourism researchers because it can be used as a general descriptor of meteorological conditions in the Atlantic and Mediterranean regions.

The dynamic evolution of the NAO is usually characterized by means of the NAO index. The index provides information about climatic variations in the Northern Hemisphere, depending on whether it has a value $>$ or $<0$. In general, the index shows 2 different phases of the NAO, one negative and the other one positive. The negative phase occurs when there is a lower-than-normal sea-level pressure over the Azores and, simultaneously, a higher-than-normal sea-level pressure over the Icelandic region. As a result of these anomalies, the Atlantic storm fronts move to the south, causing anomalously large amounts of precipitation and a higher-than-normal temperature in Europe, the western Mediterranean, and the southeastern region of North America, but drier and colder-than-normal weather in the Scandinavian countries.

In its positive phase, there is a higher-than-normal sealevel pressure over the Azores together with a lowerthan-normal sea-level pressure over the Icelandic region. In general, this phase is associated with drier and colder-than-normal conditions in Europe, the western Mediterranean, and the southeastern region of North America. On the contrary, wet and warm conditions will be observed from Iceland through Scandinavia.
The NAO index exhibits considerable inter-seasonal and inter-annual variability, and prolonged periods (several months) of both positive and negative phases of the pattern are common. Mills (2004) identified 3 components in the dynamics of the index: a slowly oscillating 'level' with long swings, a stable 'cycle' over a period of about $7.5 \mathrm{yr}$, and finally an irregular component that is responsible for a great part of the variations of the NAO index. The existence of this irregular component explains the serious difficulty in getting accurate forecasts of the index. Nowadays, there is an invigorated interest in analyzing empirically the possible relationship of the NAO index and a wide range of weather and oceanography variables, as well as its impacts on specific marine and terrestrial ecosystems (Hurrell et al. 2003). However, the economic connections have not yet been deeply explored. Through its effects on weather conditions, the NAO also has an indirect influence on certain economic activities. Some studies have empirically demonstrated the influence of the NAO on the agricultural sector (Gimeno et al. 2002, Kim \& McCarl 2005), the energy sector (Cherry et al. 2005), and marine transport (Woolf et al. 2003). The influence of the NAO on the tourism sector has not previously been studied.

The main objective of the present study is to empirically analyze whether the NAO has an important effect on international tourism demand using traditional statistical analysis and a more sophisticated technique called the autoregressive distributed lag model (ARDL) (Pesaran \& Shin 1999). The ARDL model is a methodological improvement in comparison with previous studies that applied a simple cross-correlation approach to study the connections between the NAO index and other variables, or those that made use of the Granger causality test (Wang et al. 2004, Mosedale et al. 2006). The analysis here is centered on examining the statistical relationship between the NAO and the international tourist arrivals to the Balearic Islands.

The tourism industry in this Spanish region is the main generator of employment and income, accounting directly or indirectly for around $60 \%$ of the Balearic GDP. As a consequence, government and the local tourism industry are very interested in knowing more about the determinants of tourism in the region.

\section{DATA AND METHODOLOGY}

\subsection{Data description}

There is no universally accepted index to describe the temporal evolution of the NAO phenomenon. One of the most often used indicators of NAO activity was developed by Hurrell (1995) and is formally defined as 
the mean value of the difference between the normalized sea-level pressure between Lisbon (Portugal) and Stykkisholmur (Iceland) during the winter months (December, January, February, and March). The winter value is said to describe the whole year beginning that January (Gimeno et al. 2002, Cherry et al. 2005). The annual data for the NAO index can be directly downloaded from the web page of the National Center for Atmospheric Research at www.cgd.ucar.edu/cas/ jhurrell/indices.html.

The other variable object of analysis is the international tourism demand to the Balearic Islands, which can be approximated from the number of tourist visits to the archipelago. There are other approximations, such as tourism revenues, overnight stays, or tourist expenditures; however, the number of tourist arrivals is the most common measure of tourism demand (Song \& Li 2008). The analysis in the present study is restricted to visitors from Germany and the UK. This constraint is justified because of the predominance of these 2 nationalities visiting the Balearic Islands (almost $80 \%$ of the tourist arrivals) and because for both cases there are enough data to apply the statistical methods used in the present study. The data were obtained from the yearly reports of the Centre d'Investigació de Tecnologies Turístiques de les Illes Balears (CITTIB), a tourist-statistics center run by the Balearic government, and they are available upon request at www.observatoridelturisme.caib.es.

Finally, we worked with annual data and the sample period for both time series from 1980 to 2008; therefore, the final sample covers data collected for a total of $29 \mathrm{yr}$.

\subsection{Methodology}

Three alternative methods of analysis were employed to study the empirical relationship between the NAO and international tourism demands to the Balearic archipelago. These were cross-correlation functions, the Granger causality test, and a novel, flexible, and robust methodology known as ARDL modeling.

\subsubsection{Cross-correlation analysis}

The use of cross-correlation functions is the most common method of analysis applied in natural science research to detect connections between atmospheric variability described by the NAO index and different climatic, biological, and oceanographic variables (Hurrell 1995, Gimeno et al. 2002, Orfila et al. 2005, among many others). Nevertheless, this analysis should be handled with care since if each one of the analyzed series has a very high degree of autocorrelation, then the non-zero values of the cross-correlation function do not necessarily imply a true relationship between the 2 time series (Katz 1988). In other words, the presence of autocorrelation can lead to a spurious relationship between the variables, in which case the cross-correlation analysis is not representative. In order to avoid possible fictitious cross-correlations, it is necessary to remove all of the autocorrelation in each time series and then cross-correlate that which remains. If the identical method of removing autocorrelation is applied to each variable, the true cross-correlation between variables is preserved (DeLurgio 1998).

In the present study, we specifically followed the procedure explained in Orfila et al. (2005) and Cañellas et al. (2010). We started by assuming that each one of the time series under study follows an autoregressive process with additive Gaussian noise. Consequently, the procedure implies to fit a $p$-order autoregressive model, $\operatorname{AR}(p)$, for $x_{t}$ of the form:

$$
x_{t}=\alpha_{0}+\alpha_{1} x_{t-1}+\ldots+\alpha_{p} x_{t-p}+\mathrm{e}_{t}
$$

and a $q$-order autoregressive, $\operatorname{AR}(q)$, for $y_{t}$ :

$$
y_{t}=\mu_{0}+\mu_{1} y_{t-1}+\ldots+\mu_{p} y_{t-q}+u_{t}
$$

where $x_{t}$ and $y_{t}$ are the original time series that show autocorrelation, and $\left\{\alpha_{i}\right\}_{i=0}^{p}$ and $\left\{\mu_{j}\right\}_{j=0}^{q}$ are the coefficients that must be optimally estimated in order to get non-autocorrelated residuals $\left\{e_{t}\right\}_{t=1}^{T}$ and $\left\{u_{t}\right\}_{t=1}^{T}$. The order $p$ and $q$ of the autoregressive will be those that minimize the Akaike information criterion (Akaike 1973). Finally, the residuals in Eqs. (1) \& (2) will be the filtered series to be cross-correlated.

\subsubsection{Granger causality test}

The second procedure employed here is based on the causality concept developed by Granger (1969). He presented an approach for testing causality between 2 variables that has been widely applied in many economic studies; however, it is rarely used in climate research (Mosedale et al. 2006). The procedure starts with the construction of simple causal models:

$x_{t}=\alpha_{0}+\alpha_{1} x_{t-1}+\ldots+\alpha_{p} x_{t-p}+\beta_{1} y_{t-1}+\ldots+\beta_{p} y_{t-p}+\varepsilon_{t}$

and

$y_{t}=\mu_{0}+\mu_{1} y_{t-1}+\ldots+\mu_{p} y_{t-p}+\delta_{1} x_{t-1}+\ldots+\delta_{p} x_{t-p}+u_{t}$

where $x_{t}$ and $y_{t}$ are 2 stationary time series, $\left\{\alpha_{i}\right\}_{j=0}^{p}$, $\left\{\mu_{i}\right\}_{j=1}^{p},\left\{\delta_{i}\right\}_{j=1}^{p}$ and $\left\{\beta_{i}\right\}_{j=1}^{p}$ are the parameters to be estimated, and the residuals of the models $\varepsilon_{\mathrm{t}}$ and $u_{\mathrm{t}}$ must be uncorrelated white-noise series. As usual in this kind of analysis, the best order $p$ for the equations is selected by minimizing an information criterion, e.g. the Schwarz criterion (Schwarz 1978). The definition of 
causality in the sense of Granger implies that $y_{t}$ causes $x_{t}$ if it is proved that some estimated coefficient $\beta_{\mathrm{i}}$ is statistically non-zero. Similarly, $x_{t}$ causes $y_{t}$ if it is demonstrated that some $\delta_{\mathrm{i}}$ is statistically non-zero. Moreover, if both of these events occur, it means that there is a feedback relationship between $x_{t}$ and $y_{t}$. The null hypothesis of the contrast with 2 restrictions is that $y_{t}$ does not Granger-cause $x_{t}$ in the first regression and that $x_{t}$ does not Granger-cause $y_{t}$ in the second regression. The statistical test used to contrast these hypotheses is the conventional $F$-test.

\subsubsection{ARDL bounds testing}

In recent years, considerable attention has been paid to testing for the existence of short- and long-run relationships between variables based on the use of different cointegration techniques (Engle \& Granger 1987, Johansen \& Juselius 1990). However, these methods can be applied only when the variables are integrated of the same order. This technical requirement puts a severe limitation on the traditional cointegration techniques. In order to overcome this restriction, Pesaran et al. (2001) suggested the ARDL bounds-testing approach to test for the existence of a long-run relationship between variables, which is applicable irrespective of whether the underlying variables are integrated of order zero, $\mathrm{I}(0)$, or order one, $\mathrm{I}(1)$, or a mixture of both. The ARDL approach to cointegration entails estimating the conditional error correction model (ECM):

$\Delta y_{t}=\alpha_{0}+\sum_{i=1}^{p-1} \alpha_{i} \cdot \Delta y_{t-i}+\sum_{j=0}^{p-1} \mu_{j} \cdot \Delta x_{t-j}+\delta \cdot t+\varphi \cdot y_{t-1}+\vartheta \cdot x_{t-1}+\varepsilon_{t}$

where $\Delta$ represents the first-difference operator, $y_{t}$ is the number of international tourist arrivals, $x_{t}$ is the value of the NAO index, $t$ is the tendency, the parameters $\phi$ and $\vartheta$ are the long-run coefficients, $\alpha_{i}$ and $\mu_{j}$ the short-run coefficients, and $\varepsilon_{t}$ represent the residuals. The optimal number of lags of the ECM is determined using a specific criterion of selection (e.g. the Akaike information criterion).

Following Pesaran et al. (2001), our testing procedure of a long-run relationship between tourist arrivals and NAO index is based on 2 alternative statistics. The first one is the F-test on the joint null hypothesis that the coefficients on the level variables lagged are jointly equal to zero $\left(H_{0}: \varphi=\vartheta=0\right)$. The second statistic is an individual $t$-test on the lagged dependent variable $\left(H_{0}: \varphi=0\right)$. These statistics have a non-standard distribution under the null hypothesis that no relationship exists between $y_{t}$ and $x_{t}$, irrespective of whether these variables are purely $\mathrm{I}(0)$, purely $\mathrm{I}(1)$, or a mixture of both. However, Pesaran et al. (2001) derived their asymptotic distributions under the null hypothesis and proposed critical value bounds, which allows us to accept or reject the null hypothesis. Therefore, if the statistics fall outside of their respective critical upper bound, then we reject the null hypothesis and we have evidence of a long-run relationship (indicating cointegration). If the statistics are below their respective critical lower bound, then we cannot reject the null hypothesis of no cointegration. Finally, if the statistic lies between the upper and lower critical bounds, then the inference is inconclusive.

\section{EMPIRICAL RESULTS}

\subsection{Cross-correlation analysis}

The first step in order to carry out a cross-correlation analysis between the NAO index and the number of tourist arrivals is to remove the autocorrelation existing in the original time series using an $\operatorname{AR}(p)$. Fig. 1 depicts the choice of the optimal order of the autoregressive for each series. In all cases, the optimum order that minimizes the Akaike information criterion is $p=1$, and the residuals obtained after filtering the original data did not exhibit significant autocorrelations from a statistical point of view. Therefore, the residual series can be used in the analysis to detect significant cross-correlations not due to co-temporality. Specifically, the residuals of the NAO index were cross-correlated with each one of the residuals of the international tourist arrivals series.

Fig. 2 shows the sample cross-correlation function for the German and UK cases. These figures also display the confidence intervals necessary to examine the statistical significance of the cross-correlation coefficients. The intervals are empirically constructed by means of a Monte Carlo simulation. To do this, 5000 time series were randomly generated with the same characteristics as a random white variable and with the same standard deviation as the residuals of the NAO index. Then, each one of these artificial variables was cross-correlated with the residual series of tourism arrivals. An empirical distribution of each cross-correlation coefficient for each lag was computed. Using this empirical distribution, a confidence interval with a specific significance level was built and, in this case, the significance was determined to be $95 \%$.

Analyzing the cross-correlation coefficients that appear in Fig. 2a, we can observe that the NAO exerts a statistically significant influence on the number of German visitors to the Balearic Islands at lags $\tau=4$ and $\tau=7$, and no significant cross-correlations are detected to other lags. Conversely, in Fig. 2b, a significant relationship is found at lags $\tau=2$ and $\tau=7$ for UK visitors. 

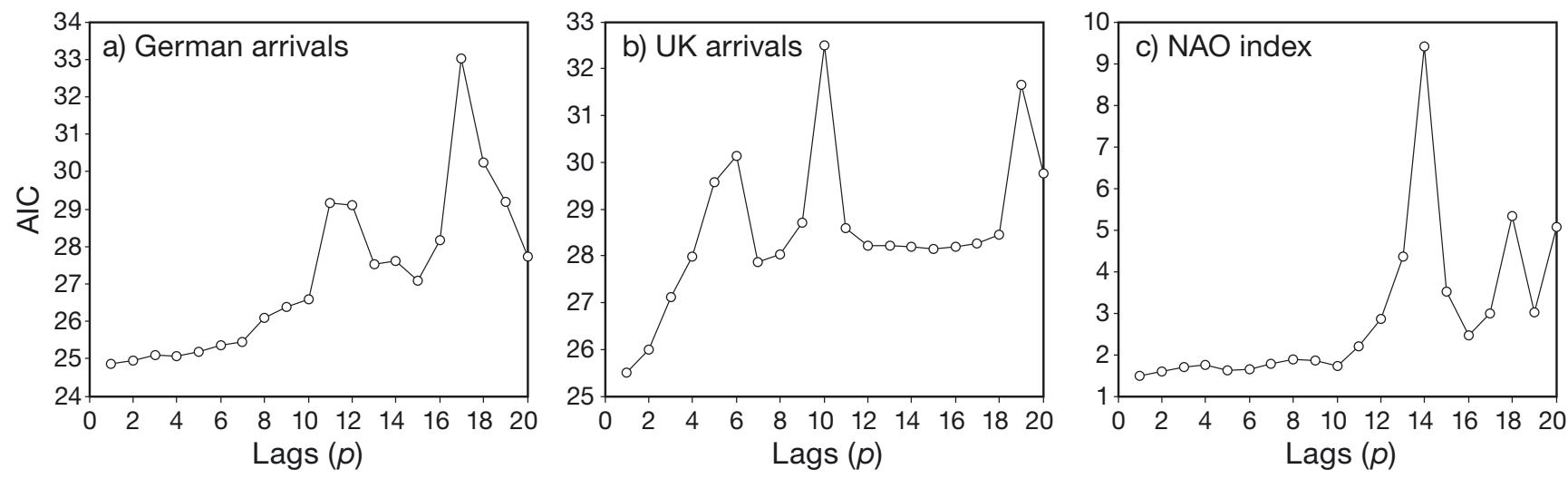

Fig. 1. Cross-correlation analysis. Choice of the optimum $p$-order of the autoregressive for the time series for tourist arrivals from (a) Germany and (b) the UK, and for (c) the NAO index. AIC: Akaike information criterion

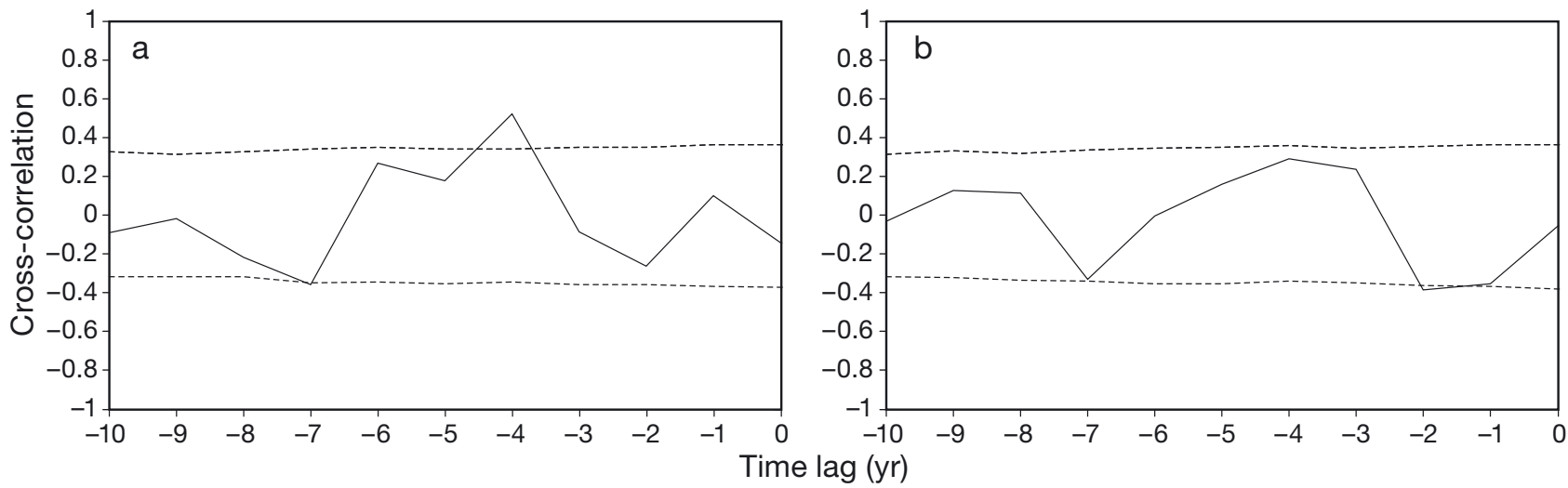

Fig. 2. Cross-correlation analysis. Sample cross-correlation between residuals of the NAO index and the residuals of tourist arrivals from (a) Germany and (b) the UK. Dashed lines: $95 \%$ confidence intervals

\subsection{Granger causality test}

In order to apply the Granger causality test, it is first necessary to verify that the time series are stationary. For this purpose, the conventional non-parametric Phillips-Perron (PP) test (Phillips \& Perron 1988) and the augmented Dickey-Fuller (ADF) test (Dickey \& Fuller 1981) were used for testing stationariness, and in particular, the existence of a unit root in the time series. The results, reported in Table 1, show that the NAO index is a stationary time series. On the other hand, tourist arrivals from Germany and the UK are both non-stationary time series. As they are I(1), a common practice to obtain stationariness is to take first differences. Therefore, first-differenced time series were used in the case of German and UK tourist arrivals.
Table 1. Phillips-Perron and Dickey-Fuller tests for unit root $\left(H_{0}\right.$ : variable that has a unit root). $\Delta$ : first-difference operator. Parentheses - Phillips-Perron test: truncation lag for the Newey-West correction length; Dickey-Fuller test: lag length based on the Schwarz information criterion. Critical values are based on MacKinnon (1996). ${ }^{*} p<0.05$. Constant, trend: $t$-statistic models with constant and trend, respectively

\begin{tabular}{|c|c|c|c|c|}
\hline \multirow[b]{2}{*}{ Variable } & \multicolumn{2}{|c|}{ Phillips-Perron test } & \multicolumn{2}{|c|}{ Dickey-Fuller test } \\
\hline & $\begin{array}{l}\text { Constant } \\
\text { and trend }\end{array}$ & Constant & $\begin{array}{l}\text { Constant } \\
\text { and trend }\end{array}$ & Constant \\
\hline NAO & $-4.45^{*}(3)$ & $-4.42 *(1)$ & $-4.48^{*}(0)$ & $-4.42^{*}(0)$ \\
\hline German arrivals & $-2.37(3)$ & $-0.30(6)$ & $-2.18(0)$ & $-0.45(0)$ \\
\hline UK arrivals & $-2.62(9)$ & $-1.89(11)$ & $-3.36(1)$ & $-1.93(0)$ \\
\hline$\Delta$ German arrivals & $-4.38^{*}(1)$ & $-4.47^{*}(1)$ & $-4.38^{*}(0)$ & $-4.47^{*}(0)$ \\
\hline$\Delta$ UK arrivals & $-5.48^{*}(4)$ & $-5.23^{*}(3)$ & $-5.05^{*}(0)$ & $-5.11^{*}(0)$ \\
\hline
\end{tabular}

Given that all series are now stationary, it is feasible to apply the Granger causality test. Table 2 shows the null hypothesis to be contrasted and the values and $p$ values of the test. The test associated a p-value of 0.01 and 0.0367 for the German and UK arrivals, respec- 
Table 2. Granger causality test. Lag length is based on the Schwarz information criterion and on the no-correlation serial of the residuals

\begin{tabular}{|lccc|}
\hline Null hypothesis & Lag & F-statistic & p-value \\
\hline NAO does not Granger-cause German arrivals & 4 & 4.88758 & 0.0100 \\
NAO does not Granger-cause UK arrivals & 5 & 3.44631 & 0.0367 \\
\hline
\end{tabular}

the tourist arrivals are both non-stationary time series at their levels, but stationary at first differences, so they are I(1).

Once we know that the order of integration is not going to be $>1$, the next step is to apply the bounds-testing approach to cointegration proposed by

tively. Therefore, the null hypothesis that the NAO does not have a causal effect on the number of tourist arrivals to the Balearic Islands from both countries can be rejected. Moreover, an analysis of the sensitivity of the results reveals that the choice of the lag length is not a critical issue. That is, the test is robust to different number of lags considered in the analysis. Therefore, the Granger test verifies statistically that a climatic phenomenon such as the NAO has a Granger causal relationship on international tourism demand to the Balearic archipelago.

\subsection{ARDL bounds testing}

The ARDL approach allows us to verify the existence of a long-run relationship between 2 variables without knowing whether they are $\mathrm{I}(1)$ or $\mathrm{I}(0)$. However, we need to be sure that the variables are not integrated of a higher order, $\mathrm{I}(\mathrm{d})$, with $\mathrm{d}>1$. For this reason, it is necessary to analyze the order of integration using a combination of statistical tests. As mentioned above (Section 3.2, Granger causality test), the ADF and PP tests revealed that the NAO index is stationary, i.e. I(0), and

Table 3. Autoregressive distributed lag (ARDL) modeling. Critical values and bounds test for cointegration for tourist arrivals from the UK and Germany. ${ }^{*}$ Statistic lies above the upper level of the band. F-statistics of the model $-F_{\mathrm{IV}}$ : unrestricted intercept and restricted trend $F_{\mathrm{V}}$ : unrestricted intercept and trend; $F_{\text {III }}$ : untrestricted intercept and no trend. $t$-statistics of the model $-t_{\mathrm{V}}$ : deterministic linear trend; $t_{\mathrm{III}}$ : no trend. I(0): integrated of order zero; I(1): integrated of order one. Constant, trend: models with constant and trend, respectively

\begin{tabular}{|c|c|c|c|c|}
\hline \multirow[t]{2}{*}{ Scenario } & \multirow[t]{2}{*}{$\begin{array}{l}\text { Constant and } \\
\text { trend }\end{array}$} & \multirow[t]{2}{*}{ Constant } & \multicolumn{2}{|c|}{$\begin{array}{c}\text { Critical values } \\
\text { (significance } \alpha=0.05 \text { ) }\end{array}$} \\
\hline & & & $\mathrm{I}(0)$ & $\mathrm{I}(1)$ \\
\hline \multicolumn{5}{|l|}{ UK } \\
\hline$F_{\mathrm{IV}}$ & $6.78^{*}$ & - & 4.68 & 5.15 \\
\hline$F_{\mathrm{V}}$ & $10.01^{*}$ & - & 6.56 & 7.30 \\
\hline$t_{\mathrm{V}}$ & $-4.45^{*}$ & - & -3.41 & -3.69 \\
\hline$F_{\mathrm{III}}$ & - & $6.368^{*}$ & 4.94 & 5.73 \\
\hline$t_{\mathrm{III}}$ & - & -3.14 & -2.80 & -3.21 \\
\hline \multicolumn{5}{|l|}{ Germany } \\
\hline$F_{\mathrm{IV}}$ & 3.01 & - & 4.68 & 5.15 \\
\hline$F_{\mathrm{V}}$ & 4.52 & - & 6.56 & 7.30 \\
\hline$t_{\mathrm{V}}$ & -2.16 & - & -3.41 & -3.69 \\
\hline$F_{\mathrm{III}}$ & - & 1.42 & 4.94 & 5.73 \\
\hline$t_{\mathrm{III}}$ & - & -0.175 & -2.80 & -3.21 \\
\hline
\end{tabular}

Pesaran et al. (2001). Following these authors, the Akaike information criterion was used in selecting the optimum lag length ( $p$ ) in Eq. (5).

Table 3 shows the results of the bounds test for cointegration between the NAO index and tourist arrivals from the UK and Germany to the Balearic archipelago, respectively. The bounds-testing analysis is carried out employing 3 different scenarios as suggested by Pesaran et al. (2001). The first one considers an ARDL model with restricted deterministic trends $\left(F_{\mathrm{IV}}\right)$; the second one uses a model with unrestricted deterministic trends $\left(F_{\mathrm{V}}\right.$ and $\left.t_{\mathrm{V}}\right)$; and, finally, a model without deterministic trends ( $F_{\text {III }}$ and $t_{\text {III }}$ ) is used. In these tables, the critical values for $F$ - and $t$-statistics are also shown, and they were taken from Pesaran et al. (2001).

The results shown in Table 3 suggest the existence of a level relationship (long-run causality) between the NAO index and tourist arrivals from the UK to the Balearic Islands. The F-statistics lie above the upper bound of the critical values for all scenarios $F_{\text {III }} F_{\text {IV }}$, and $F_{\mathrm{V} i}$ therefore, we can reject the null hypothesis $H_{0}: \varphi=\vartheta=0$. Regarding the $t$-statistics, the results obtained in the scenario $t_{\mathrm{V}}$ corroborate the existence of a relationship between the variables since the test value allows us to reject the null hypothesis $H_{0}: \varphi=0$. However, for the scenario $t_{\mathrm{III}}$, the statistic provides a value that lies between the upper and lower critical values; consequently, the inference is inconclusive.

On the other hand, results in Table 3 for the German case reveal that both the $F$ - and $t$-statistics are below their respective critical lower bound for all scenarios; therefore, they do not support a long-run relationship between the NAO index and tourist arrivals from Germany.

\section{SUMMARY AND CONCLUSIONS}

Tourism is evidently connected with climate and weather. However, the tourism literature has paid little attention to the influence of meteorological factors to explain tourism flows. In fact, 
the great majority of the international tourism-demand models do not include climate and weather conditions as explanatory variables. The main objective in the present study was to underline that meteorological factors matter in tourism, and that they must be taken into account. Specifically, we investigated the existence of a statistical relationship between one of the most important modes of atmospheric variability, the NAO, and international tourism demand to the Balearic Islands. We used techniques usually applied in the natural sciences to statistically analyze connections between variables: cross-correlation functions and the Granger causality test. Besides these traditional techniques, we also used a novel and flexible methodology, the ARDL bounds-testing approach.

From our point of view, the present study makes some important contributions to the existing literature about tourism and meteorology:

(1) Although previous studies had already statistically examined the influence of the NAO in some economic sectors such as energy, agriculture, and transport activities, our study is the first one where the influence of the NAO on tourism has been researched.

(2) To the best of our knowledge, this is also the first time that an ARDL bounds-testing approach has been applied in climate research. The use of the ARDL approach implies a methodological improvement since it is a robust and flexible technique that can be used to discover long-run relationships.

(3) Our results corroborate the fact that the NAO has a significant effect on the number of tourists arriving in the Balearic Islands. The Granger approach revealed a causal relationship in a Granger sense between the NAO and the number of visitors from the UK and Germany. This finding was confirmed by cross-correlation analysis. Finally, the ARDL bounds-testing approach verified the existence of a long-run relationship between the NAO index and tourism demand from the UK, but this connection was not statistically supported for German tourist arrivals.

(4) These results imply that the NAO index can be useful to tourism researchers. The index is considered to be a general descriptor of the meteorological conditions in the Atlantic and Mediterranean regions, and the present study has demonstrated a statistically significant connection between the NAO index and the number of tourist arrivals to the Balearic archipelago. Therefore, when constructing a tourism-demand model, the NAO index can be a valuable explanatory variable for 2 reasons. First, we can obtain parsimonious models since we can introduce into the model meteorological information using only 1 variable (principle of parsimony). Second, the NAO index as an explanatory variable allows a researcher to avoid some econometric problems (e.g. multicollinearity).
(5) The meteorological information summarized in the NAO index can be useful in the operational decision-making processes and risk management of businesses in the tourism sector.

Finally, in spite of the promising results, the present study represents only a first step that opens a new line of research possibilities. Further research will be needed in order to construct a tourism-demand model that includes the NAO index as an explanatory variable. Such a model would allow us to quantify and explain in more detail the impact of the NAO on tourism.

Acknowledgments. This research was funded by Grant 09TUR004300PR from Xunta de Galicia. M.A.D. also acknowledges financial support (MTM2008-03129; FEDER funding included) from the Spanish Ministerio de Educación y Ciencia, and also from Grant PGIDIT06PXIC300117PN from Xunta de Galicia. We also appreciate the reviews and suggestions provided by anonymous referees which noticeably improved the quality of this manuscript.

\section{LITERATURE CITED}

Agnew M, Palutikof J (2006) Impacts of short-term climate variability in the UK on demand for domestic and international tourism. Clim Res 31:109-120

Agnew M, Viner D (2001) Potential impacts of climate change on international tourism. Tourism Hospitality Res 3:37-60

Akaike $H$ (1973) Information theory and an extension of the maximum likelihood principle. In: Petrov B, Csake F (eds) Proc 2nd Int Symp Information Theory. Akademiai Kiado, Budapest

Berrittella M, Bigano A, Roson R, Tol R (2006) A general equilibrium analysis of climate change impacts on tourism. Tourism Manag 27:913-924

> Cañellas B, Orfila A, Méndez F, Álvarez A, Tintoré J (2010) Influence of the NAO on the northwestern wave climate. Sci Mar 74:55-64

Cherry J, Cullen H, Visbeck M, Small A, Uvo C (2005) Impacts of the North Atlantic Oscillation on Scandinavian hydropower production and energy markets. Water Resour Manag 19:673-691

> de Freitas CR (2003) Tourism climatology: evaluating environmental information for decision-making and business planning in the recreation and tourism sector. Int J Biometeorol 48:45-54

de Freitas CR, Scott D, McBoyle G (2008) A second generation climate index for tourism (CIT): specification and verification. Int J Biometeorol 52:399-407

DeLurgio SA (1998) Forecasting principles and applications. Irwin/McGraw-Hill, New York, NY

> Dickey DA, Fuller WA (1981) Likelihood ratio statistics for autoregressive time series with a unit root. Econometrica 49:1057-1072

Engle RF, Granger CWJ (1987) Cointegration and error correction: representation, estimation and testing. Econometrica 55:251-276

> Gimeno L, Ribera P, Iglesias R, Torre L, García R, Hernández E (2002) Identification of empirical relationships between indices of ENSO and NAO and agricultural yields in Spain. Clim Res 21:165-172

Granger CWJ (1969) Investigating causal relations by econo- 
metric models and cross-spectral methods. Econometrica $37: 424-438$

Greatbatch RJ (2000) The North Atlantic Oscillation. Stochastic Environ Res Risk Assess 14:213-242

Hurrell J (1995) Decadal trends in the North Atlantic Oscillation: regional temperatures and precipitation. Science 269: 676-679

Hurrell J, Kushnir Y, Ottersen G, Visbeck M (2003) An overview of the NAO, climatic significance and environmental impact. Geophys Monogr 134. American Geophysical Union, Washington, DC

Johansen S, Juselius K (1990) Maximum likelihood estimation and inference on cointegration with applications to the demand for money. Oxf Bull Econ Stat 52:169-210

Katz RW (1988) Use of cross correlation in the search for teleconnections. Int J Climatol 8:241-253

Kim M, McCarl BA (2005) The agriculture value of information on the North Atlantic Oscillation: yield and economic effects. Clim Change 71:117-139

Law R, Au N (1999) A neural network model to forecast Japanese demand for travel to Hong Kong. Tour Manage 20:89-97

Lim C (1999) A meta-analytic review of international tourism demand. J Travel Res 37:273-289

MacKinnon JG (1996) Numerical distribution function for unit root and cointegration tests. J Appl Econometr 11:601-618

Maddison D (2001) In search of warmer climates? The impact of climate change on flows of British tourists. Clim Change 49:193-208

Mills TC (2004) Is the North Atlantic Oscillation a random walk? A comment with further results. Int J Climatol 24: 377-383

Mosedale TJ, Stephenson DB, Collins M, Mills TC (2006) Granger causality of coupled climate processes: ocean feedback on the North Atlantic Oscillation. J Clim 19:1182-1194

Orfila A, Álvarez A, Tintoré J, Jordi A, Basterretxea G (2005) Climate teleconnections at monthly time scales in the

Editorial responsibility: Gerrit Hoogenboom,

Griffin, Georgia, USA
Ligurian Sea inferred from satellite data. Prog Oceanogr 66:157-170

Parrilla JC, Font AR, Nadal JR (2007) Accommodation determinants of seasonal patterns. Ann Tourism Res 34: 422-436

Pesaran MH, Shin Y (1999) An autoregressive distributed lag modelling approach to cointegration analysis. In: Strom S (ed) Econometrics and economic theory in the 20th century: The Ragnar Frisch Centennial Symposium. Cambridge, University Press, Cambridge

> Pesaran M, Shin Y, Smith R (2001) Bounds testing approaches to the analysis of level relationships. J Appl Econometr 16: 289-326

- Phillips PCB, Perron P (1988) Testing for a unit root in time series regressions. Biometrika 75:335-346

> Schwarz G (1978) Estimating the dimension of a model. Ann Stat 6:461-464

Scott D, Gossling S, de Freitas CR (2008) Preferred climates for tourism: case studies from Canada, New Zealand and Sweden. Clim Res 38:61-73

Song H, Li G (2008) Tourism demand modelling and forecasting - a review of recent research. Tourism Manag 29: $203-220$

UNWTO (2009) World tourism barometer. World Tourism Organisation, 7, 2 June 2009. www.world-tourism.org/facts/ wtb.html

> Wang W, Anderson BT, Kaufmann RK, Myeni RB (2004) The relation between the North Atlantic Oscillation and SSTs in the North Atlantic basin. J Clim 17:4752-4759

Woolf DK, Coll J, Gibb S, Challenor PG (2003) Sensitivity of ferry services to the Western Isles of Scotland to changes in wave climate. In: Proc OMAE'04, 23rd Int Conf Offshore Mechanics and Arctic Engineering, Vol 2. Vancouver, 20-25 June 2004. American Society of Mechanical Engineers, New York, NY, p 361-370 doi:10.1115/OMAE 2004-51427

Submitted: March 30, 2010; Accepted: September 3, 2010 Proofs received from author(s): October 11, 2010 